\title{
Behind the paper: Stepping up to the antiplatelet
}

In March 2002, a middle-aged man was admitted to the German Heart Centre in Munich to receive treatment for a blocked coronary artery. After undergoing balloon angioplasty and having a stent implanted, the man needed some sort of blood-thinning therapy, yet aspirin, the workhorse treatment for preventing arterial clots, gave him asthma attacks. His cardiologist, Nicolas von Beckerath, turned to clopidogrel, an antiplatelet drug that had been approved in the EU four years earlier under the brand name Plavix. The man tolerated the drug well, but clopidogrel did not seem to inhibit his platelet activity, even at very high doses.

"Surprisingly, we saw that this patient was absorbing the drug very well, but he wasn't metabolizing it," says von Beckerath, now at the Viersen General Hospital in Germany.

Perplexed, von Beckerath phoned his colleague Dirk Taubert, a pharmacologist at the University Hospital of Cologne, to inquire why the drug didn't seem to work. Unfortunately, Taubert wasn't much help. "I knew that the drug existed and that it worked as an antiplatelet agent... but not much more," Taubert says. "At that moment, I was peeved at myself that I could help neither the patient nor my colleague, and that I knew so little about clopidogrel."

Determined to find out why the medication was effectively useless for this individual and other patients, Taubert and von Beckerath developed an assay to measure the concentrations of clopidogrel metabolites in blood plasma. The researchers then ran a series of clinical trials and used the assay to show that individual variability in drug response could be chalked up to limited availability of clopidogrel's active metabolite in some people ${ }^{1,2}$.

Buoyed by these findings, Taubert went hunting for the gene responsible for the variable responses to clopidogrel. But before he could find the answer, several independent research teams reported that polymorphisms in the gene encoding a particular cytochrome P450 enzyme, CYP2C19, explained why some people have lower plasma levels of the active metabolite of clopidogrel and, thus, higher risks of heart disease ${ }^{3-5}$.

These studies, however, were based solely on genetic associations, notes Taubert. "They had no mechanistic data," he says. So Taubert and his colleagues combined clopidogrel with extracts from human cells expressing cytochrome P450 enzymes in vitro and showed that the drug did not seem to convert to its active form 6 . Thus, Taubert concluded that cytochrome P450 is not the crucial enzyme responsible for clopidogrel activation.

Further evidence that the CYP2C19 gene has no bearing on drug response came last October when a team including Deepak Bhatt, chief of cardiology at the Veteran Affairs Boston Healthcare System, genotyped more than 6,000 individuals with acute coronary syndromes or atrial fibrillation and found that people showed similar clopidogrel responses, irrespective of their CYP2C19 genetic status ${ }^{7}$.

To pinpoint the enzyme behind clopidogrel activation, Taubert, in collaboration with investigators at the St. Antonius Hospital Nieuwegein in the Netherlands, expressed cytochrome P450 enzymes as well as esterases - enzymes often involved in

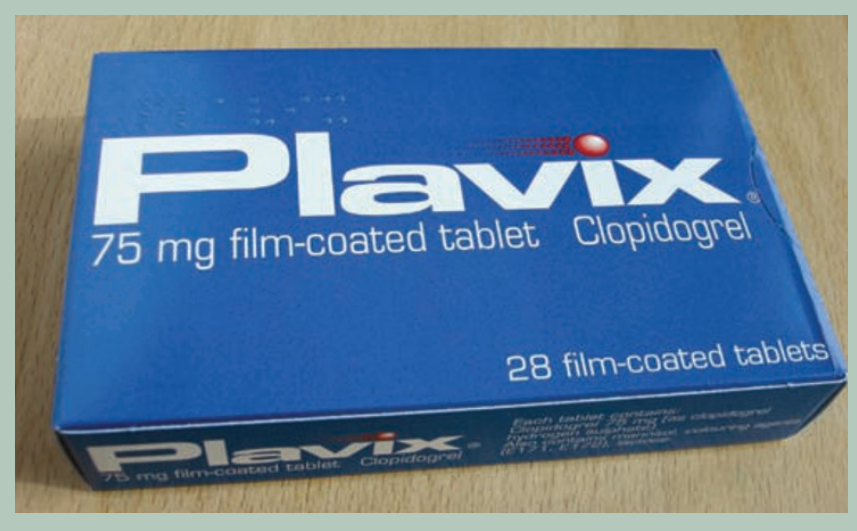

Researchers discover why some people don't respond to the blood-thinner.

drug metabolism that break up ester molecules into acids and alcohols - in human cell cultures and measured the breakdown of clopidogrel in extracts from these cells. The researchers found that cytochrome P450 enzymes were needed to first break down the drug to an intermediate metabolite, but an esterase called paraoxonase-1 (PON1) further transformed the drug into its active state. "Two steps are involved," says Taubert. "And the second step is the rate-limiting step of the bioactivation."

Further tests in two cohorts of people with coronary artery disease who underwent stent implantation and took clopidogrel for at least 6 months showed that a single amino acid change in the PON1 sequence highly correlated with the clinical efficacy of the drug, Taubert's team reports on page 110 (ref. 8).

"It's a very important finding," says Bhatt. "Some further replication is needed, but the core findings, if they hold up, are very substantial, because the polymorphisms that have been identified to date seem to have relatively low predictability. If this finding can be duplicated in multiple, diverse populations, there's a good chance that this could guide therapy to improve patient outcomes."

Taubert has since gone back to check the genotype of the man who inspired his decade-long research project. Consistent with Taubert's recent results, the man is homozygous for the genetic variant associated with low PON1 activity and poor response to clopidogrel. "This all fits, but the explanation came with a delay of a few years," Taubert says. Fortunately, the man has not suffered any additional heart problems, even without taking any antiplatelet agents.

\section{Elie Dolgin}

1. Taubert, D. et al. Thromb. Haemost. 92, 311-316 (2004).

2. von Beckerath, N. et al. Circulation 112, 2946-2950 (2005).

3. Brandt, J.T. et al. J. Thromb. Haemost. 5, 2429-2436 (2007).

4. Kim K.A., Park, P.W., Hong, S.J. \& Park, J.Y. Clin. Pharmacol. Ther. 84, 236-242 (2008).

5. Mega, J.L. et al. N. Engl. J. Med. 360, 354-362 (2009).

6. Taubert, D., Bouman, H.J. \& van Werkum, J.W. N. Engl. J. Med. 360, 2249-2250 (2009).

7. Paré, G. et al. N. Engl. J. Med. 363, 1704-1714 (2010).

8. Bouman, H.J. et al. Nat. Med. 17, 110-116 (2011). 